\title{
Emil H. Schemitsch, Michael D. McKee (eds): Operative techniques: orthopedic trauma surgery
}

\author{
Saunders Elsevier, 2010; 930 pp.; numer. Figs.; 280.00 US\$ (companion website, \\ with video), ISBN: 978-1-4160-4935-7
}

Pierre Kehr

Received: 24 November 2011/ Accepted: 26 November 2011/Published online: 20 December 2011

(C) Springer-Verlag 2011

It acts above all of a practical book, practically a guide, of surgical techniques relating to almost all orthopedic traumatology, of the upper limb than the lower extremity while passing by the spine and the pelvis.

Each chapter relates to a type of fracture. This one is presented clearly with explicit drawings and operational sights. The other therapeutic possibilities are presented briefly. The shelves are presented at the beginning of chapter before the discussed points. The technique is described step by step.

This book will interest all the inexperienced surgeons, who thanks to the simple explanations will not be rejected by a novel method.
Moreover, one DVD and an Internet access make it possible to usefully supplement the book with video movies and further information (in particular a bibliography).

Moreover, when several techniques are possible (for example, nailing and plates) two chapters are then presented.

A book to be recommended to the young and experienced traumatologists.

Alain Graftiaux

Conflict of interest No funds were received in support of this study.

P. Kehr $(\bowtie)$ 